\title{
Is the economic crisis over (and out)?
}

\author{
KARIM M. ABADIR* \\ Imperial College London
}

\begin{abstract}
This note analyzes the recent global recession: its causes, the predictability of the timing of its start and of its end, and the implications for macro policy. These follow from the general-equilibrium macro model of Abadir and Talmain (2002) and its implications for a new type of macroeconometrics. The note also proposes some banking regulations, and presents prospects for the future.
\end{abstract}

Keywords: recession, recovery, causes and symptoms, turning points, prediction, macro policy

JEL Classifications: E30, E44, E50, E62, C50

\section{Introduction and plan}

A global recession has happened and we need to ask ourselves some fundamental questions:

1. Was it predictable? Many observers and economists (including econometricians) were taken by surprise by the advent and strength of the recession.

2. What were its causes, and how did they manifest themselves? Keep in mind that causes and symptoms can differ. For example, many believe the recession was caused by the financial crisis, but this is only partly true as we shall see.

3. Is the recovery robust? What should we expect next? Can policymakers learn any lessons to soften the next recession (there will certainly be another one) and to come out of this one without hiccups?

This note presents some answers to these questions in an accessible way. Reference is also given, where relevant, to the technical work that was used in forming an answer to these questions.

*I am grateful for comments from the referee and the editor, and for support from ESRC grant RES062230790.

(C) 2011 Karim M. Abadir. Licenced under the Creative Commons Attribution-Noncommercial 3.0 Licence (http: //creativecommons.org/licenses/by-nc/3.0/). Available at http://rofea.org. 


\section{Patterns and predictions}

The crisis was predicted by a few, including myself on two public occasions. The first of these was my inaugural lecture at Imperial College on 21 June 2007, the second being a Bank of England seminar on 15 August 2007, before the subprime crisis hit the US. Back then I said that a recession will happen if the US does not reduce interest rates, and it will be transmitted to the rest of the world.

Lest the reader think I am a prophet of doom, the recovery was also predictable and I did so in a Distinguished Visiting Professor's general talk at the American University in Cairo on 22 April 2009. It was a time when questions were being raised about the survival of the capitalist system and comparisons made with the protracted Great Depression. I said then that the US will recover first, within a year, but that Europe will take longer and will be worse off in the meantime. The lecture is available on their website and mine.

These are not crystal-ball predictions! In Abadir and Talmain (2002), the solution of a micro-founded general equilibrium model of the economy presented us with a new type of dynamics not seen hitherto in the academic literature. The paper demonstrated the need for new and unconventional econometric techniques that were later introduced in Abadir, Caggiano, and Talmain (2005) for single variables, then Abadir and Talmain (2008) for multiple variables. This line of work is summarized in Abadir and Talmain (2011).

Policymakers must be able to read what the data say, if they are to act in a timely and proportionate way. If there is a practical message to be retained from Abadir et al. (2005) in particular, it is the following. Our model predicts that changes in economic policy take time to work through the system, but not in a gradual way as was previously thought. Instead, there is a long sequence of small signs of a slowdown, then a seemingly abrupt decline. Existing models cannot cope with these patterns. When only the small signs have appeared, no-one using existing models would be able to guess the substantial turning point that is about to occur. This is because these models misinterpret the inertia and project it into the future, hence missing the 'sudden' turns. ${ }^{1}$

What are the implications of the model for policymakers? If a policy intervention is needed to counter the signs of a slowdown, the stimulus that is applied to the economy:

1. should be timed to start well before the abrupt decline;

2. will take a long time to have an impact;

\footnotetext{
${ }^{1}$ The autocorrelation functions (ACFs) obtained in Abadir and Talmain (2002) and Abadir et al. (2005) indicated two main features. The variables are very persistent initially: whatever shock hits the economy appears to have little impact in the near future. However, unlike unit-root processes, this persistence changes substantially afterwards, and there is a change of response to the shock. Intuitively, this happens in the Abadir and Talmain (2002) model because the shock works its way slowly through the heterogeneous firms until it eventually surfaces in an amplified way.
} 
3. should be sufficiently aggressive to achieve the objective, but take into account the increments that will keep occurring afterwards; and

4. revert to a neutral stance well before the objective is achieved, letting the economy ease onto its intended path.

Consequently, a gradualist macroeconomic policy will not yield the desired results: it will be a case of too little and too late.

How can we read in the data the early signs of a change of direction? There are two levels at which this question can be answered. The first one is from microeconomic data, and this is the approach that I used and that will be highlighted at the start of Subsection 3.1 below: by observing the performance of the firms in the economy and following through the impact on the macroeconomy. It is a logical/qualitative approach that is based on the literature cited earlier, but it is more casual than the next one. It is also a coarse approach that can only detect large future changes in one direction or the other, but cannot be used for fine-tuning.

The second approach relies on fitting reduced-form dynamic models to macroeconomic data. An illustration of it has been given in the second application in Abadir and Talmain (2008), where we explained our method of calculating the time path depicting the adjustment of a macro variable (S\&P500 in that instance) towards its fundamental value.

\section{Causes and symptoms}

So where did the crisis come from, on the ground, and how would it show up in the variables? This can be summarized in three subsections, two about the sectors where the crisis hit, and one about the interaction between them. The first subsection is the one that relates to the author's work mentioned earlier, the rest following from standard economic analysis.

\subsection{The real economy}

The initial trigger was a macro slowdown whose seeds started as early as 2006, possibly due to the increasingly high oil prices and other factors. The sequence was:

1. Profit warnings and restructuring announcements. There was a series of unusually large number of such announcements, coming from a wide cross-section of US-listed corporations that are a bellwether for the economy. ${ }^{2}$ As a result of these, future layoffs were

\footnotetext{
${ }^{2}$ It was one of the highest jumps in profit warnings in recent decades, with a double-digit percentage jump. Record-breaking rates of warnings were also recorded in the UK; e.g. see the calculations by Ernst \& Young publicized in http://news.bbc.co.uk/1/hi/business/7185603.stm, where only 1 in 5 annual warnings in 2007 were due to the credit crunch.
} 
already announced and their effect was inevitable. ${ }^{3}$ Before we go on to analyze these effects, we remind the readers that our model is a micro-founded one where economywide shocks are the most potent source of disturbance that gets amplified; see Abadir and Talmain $(2002$, pp. 763, 770). These economy-wide shocks can be identified from such micro announcements.

2. Income reduction. Profits came in lower than usual, on a national level, hence reducing GDP through the national income identity. But the announced layoffs would also affect the labour force, especially at the lower-income end where the propensity to consume is highest.

3. Housing crisis. With the dip in income came a dip in demand for housing and inability to pay back mortgages, including defaults. The reduction in house prices accelerated a bursting of the financial bubble (prices had already started to tail off due to higher mortgage rates).

4. Consumer spending dip. This followed as a result of the previous two items. There was a double whammy of income and wealth effects on consumption.

5. Cut in investments. With reduced demand came further cuts in investments. Apart from it being the logical conclusion of the first round of the vicious circle, it was evidenced in the markets by further rounds of restructuring announcements being made by the same corporations, such as the telecom giant Nortel that eventually went bust. The short-term announcements carried the news of more layoffs in the near future, but also important was the longer-term effect of a reduction in investment: a shrinking productive capacity.

And the vicious circle went on.

The US is the main engine of the world economy. It was clear that the rest of the world would not be immune to a large shock in the US: once the US got stuck, the malaise would be transmitted abroad. The early microeconomic signs in item 1 above were widespread and repeated across such a broad cross-section that it was clear an economy-wide shock had taken place and that it would be magnified as in Abadir and Talmain (2002). For this reason, a more expansionary US economic policy was needed to counter the effect of the shock before it set the vicious circle in motion.

\subsection{The banking sector}

The incentive systems in the financial sector were (and still are) based on returns only, and not on any measure of risk. Bonuses are paid within a year, whereas the riskiness of the deal (e.g.

${ }^{3}$ Employment levels were not immediately affected, but employment expectations were. This is particularly important since these layoff announcement are usually not specific about who is to be laid off, hence raising the uncertainty faced by more workers than necessary. 
loan) is revealed over time, but it is too late to adjust the bonus. The trader/manager may have even moved on elsewhere. The result is a moral-hazard problem, encouraging risk-taking.

In the frail economy described in the past subsection, defaults increase in a snowball effect. The banks take a large hit (they need better dynamic measures of risk) and their reaction feeds back into the real economy as we shall see.

\subsection{Feedback from the banking sector to the rest}

Then there is a knee-jerk reaction: banks wake up to 'risks' and cut lending. The banks holding back lending is effectively a contraction of the money supply, via the money-supply multiplier. This is equivalent to a more restrictive monetary policy, even if interest rates were kept constant by Central Banks (CBs). It needed to be neutralized by governments and CBs, with additional liquidity and loan guarantee schemes for banks (unusual) and depositors (mostly in existence already).

But what if the initial macro trigger was not there? The financial system would have continued to 'work' (a better description would be 'limp along'). The financial markets would display excess volatility and overreaction to events. The real economy would have to cope with higher uncertainty: investment spending would be more volatile and/or less forthcoming, with negative effects on the productive capacity of the economy.

\section{Lessons learnt? What next?}

As predicted, the recession in the US is over, while Europe struggles. Given the analysis listed earlier, can we say that the crisis is resolved? A recession will happen again (by the definition of high and low), but this type of crisis is different. Unfortunately, we have had only a fix, not the structural adjustment that is needed to prevent the same type of crisis from happening again.

\subsection{Problems with current policy, 1: macro reaction}

The resuscitation of a patient is harder than having stopped the bleeding in the first place! Prompt and adequate intervention can prevent problems from developing. The US apart, CBs were way too late and timid in their reaction. The US Fed reacted admirably once it had identified the problem, albeit with a delay of about a year, while the ECB was raising rates as late as August 2008! The lesson should be learnt for the next slowdown, and the correct macroeconomic model (hence predictor) should be used.

\subsection{Problems with current policy, 2: banking regulation}

There are two main points to address here. First, the issue of moral hazard is still with us: the capping of boards' compensation is not the relevant answer, nor are share-option schemes ${ }^{4}$

\footnotetext{
${ }^{4}$ These are subject to prisoners' dilemma: if your colleagues in the bank are taking risks, you'd better do the same and get a bonus regardless of whether or not the company does well as a result. An individual
} 
for employees. Second, incorrect risk measurement (hence incorrect risk management and monitoring) still prevails.

One simple solution for the moral hazard is deferred cash compensation, which exists already but rarely: the bonus from a deal goes into a deposit that can be withdrawn after $n$ years, but not before, and only if the deal is revealed not to be a write-off. The problem in its implementation is that financial institutions compete for talent, and this is why international regulation is required on this. The crisis having passed for now, we may have missed a moment of opportunity where there was more international willingness to act.

One solution for the risk measurement issue can be implemented relatively easily. The development of the relevant theory has progressed a lot: from variance to value-at-risk (one-tail risk), extreme-value theory (already well developed in statistics and implemented in a variety of real-life engineering problems); from i.i.d. models to ones with heterogeneous firms that interact, and ones with dynamics (including predictive macroeconomic indicators). These developments are continuing. Regulators and firms should be at the forefront of these techniques and use them in their monitoring. It is impossible for regulators to muster the resources to match even a fraction of one of their watched banks. A large burden of supervision therefore falls internally on the firm. Shareholders should be informed of the latest benchmark measures and how their company is performing on these. ${ }^{5}$ Furthermore, boards of directors should be made (partially) liable for large losses incurred by mismanagement of their firm, thus giving them too an incentive to monitor properly.

\subsection{Problems with current policy, 3: prospects of slipping back or inflation?}

Because of the shrinking productive capacity (see earlier) coupled with generous government spending and expansive monetary policy, there will be a risk of demand-pull inflation this time, unlike the cost-push of the 70's. Recall that the monetary base has been expanded massively during the crisis, so when banks start lending again, the money-supply multiplier will be rising again and will increase money supply even further.

Government deficits must be reduced, but not through tax increases across the board, as we should beware of Ricardian equivalence. Fiscal constraints will require the reallocation of the tax burden. Already, Europe has started cutting budget deficits, but prematurely since the recovery has not taken hold and the early signs of overheating have not happened yet; cf. the first item of the sequence in Subsection 3.1 where early signs and their impacts are explained. Europe and the US are on increasingly diverging paths with regard to fiscal restraint and recovery/inflation. Export-led economies in Europe will do well, but the others will slow

measure of performance is needed, rather than a collective one like the share price.

${ }^{5}$ It may be said that the shareholders have no real incentive to monitor their board, if they are assured that they will be bailed out by monetary authorities. However, the uncertainty in whether or not their firm will be bailed out introduces an element of risk-sharing that produces an incentive for shareholders to monitor. 
down again due to the fiscal cuts. Some of the GIPSI ${ }^{6}$ countries had no choice but to implement these cuts because of their inability to fund further deficits.

\section{References}

Abadir, K.M., G. Caggiano, and G. Talmain. 2005. Nelson-Plosser revisited: the ACF approach. Working Paper Series 18-08, Rimini Centre for Economic Analysis (updated version of DP 2005_7, Department of Economics, University of Glasgow).

Abadir, K.M. and G. Talmain. 2002. Aggregation, persistence and volatility in a macro model. Review of Economic Studies 69: 749-779.

Abadir, K.M. and G. Talmain. 2008. Macro and financial markets: the memory of an elephant? Working Paper Series 17-08, Rimini Centre for Economic Analysis.

Abadir, K.M. and G. Talmain. 2011. The unconventional dynamics of economic and financial aggregates. Chapter 8 in: A. Ullah and D. E. A. Giles (eds.) Handbook of Empirical Economics and Finance, Chapman \& Hall/CRC.

${ }^{6}$ GIPSI may be less appetizing than PIIGS, but has the advantage that the first three happened in sequence! 